\title{
The disabled living centre: What does it do?
}

\author{
M Anne Chamberlain, Julia Gallop
}

\begin{abstract}
Seventy five consecutive users of the Leeds disabled living foundation were surveyed. Two thirds of these users were at least moderately severely disabled. Forty eight of the 65 people (74\%) who completed the questionnaire were recommended aids, and $33 \mathrm{had}$ received some at the end of the survey. Only 10 of 28 people had received recommended adaptations.

Few referrals were made to the centre by doctors. It is important that they tell their patients of this useful service.
\end{abstract}

\section{Introduction}

Disabled living centres have existed for some 16 years, and although there are perhaps not as many as are needed and the Royal College of Physicians' Report $^{1}$ recommends one per district, they are nevertheless spread across the United Kingdom and are also to be found in many areas of the world.

The first centre was the Disabled Living Foundation, which opened in London in 1971. All other centres are modelled on it to some extent and provide a similar type of service to disabled people and to professionals in rehabilitation. Not much research and and Chamberlain reviewed those that were in existence in 1977 on behalf of this unit, ${ }^{2}$ and more recently Aina carried out a study of the centre in Southampton. ${ }^{3}$ The general consensus among staff of centres is that they enable disabled people to look at and try out technical aids and equipment which may reduce their handicap and improve their independence. Professional help is always available from the centres, usually from qualified physiotherapists and occupational therapists. In addition, most centres aim at educating professionals in the surrounding area. Staff in many centres are concerned that they are not reaching all those who need them.

This study was designed to provide information about disabled visitors to one centre over a defined short period. We wished to have a profile of these people and investigate the results of their visits, hoping that such information would be helpful to the centre staff and its council.

\section{Rheumatology and Rehabilitation Research Unit, School of Medicine, University of Leeds, Leeds LS2 9PJ \\ $M$ Anne Chamberlain, FRCP, consultant rheumatologist Julia Gallop, DIPCoT, occupational therapist}

Correspondence to: Professor Chamberlain.

\section{Method}

A structured questionnaire was designed and piloted for the use of staff and visitors to the disabled living centre and the survey conducted by one researcher (JG), who was not a member of the staff, during 1986. Part I of the questionnaire was completed by the therapist employed by the centre after she had finished with the disabled visitor. Biographical details were supplemented by information given by the visitor concerning the diagnosis, type and degree of disability, use of aids and equipment, and route of referral. Part II of the questionnaire was given to the visitor to be evaluation of centres have been carried out, though Jeff

completed when all aids and equipment had been in use for two weeks. If visitors did not return the questionnaire they were contacted at three months and again at six months. Information was sought on what action was taken after the visit to the centre to determine which aids and adaptations had been ordered, which had been obtained, what the delay was, and how satisfactory the visitor found them.

To get an idea of the degree of disability visitors were asked to grade their level of dependence in feeding, cooking, bathing, toileting, dressing, walking, use of stairs, and participation in hobbies on a 10 point scale: 0 , total dependence; 5 , needing some help; 10 , totally independent with or without aids. Intermediate gradings were used. As regards satisfaction with the aids supplied the user was asked to grade this on a four point scale: 4, highly satisfactory; 3 , satisfactory; 2 , fairly satisfactory; 1 , unsatisfactory.

\section{Results}

Seventy five consecutive visitors to the centre took part in the survey, 65 completing the questionnaire, giving a response rate of $86 \%$. The sample consisted of $51(68 \%)$ females and $24(32 \%)$ males whose ages ranged from 2 to 85 years. The average age of the females was 59 years, some six years older than the males.

TABLE I-Diagnoses of 65 visitors to the disabled living centre

\begin{tabular}{lc}
\hline Diagnosis & Nos of visitors \\
\hline Osteoarthritis & 15 \\
Rheumatoid arthritis & 7 \\
Multiple sclerosis & 7 \\
Respiratory related disease & 7 \\
Cerebral palsy & 5 \\
Cerebrovascular accident & 4 \\
Lower limb amputation & 4 \\
Ankylosing spondylitis & 2 \\
Parkinson's disease & 2 \\
Paraplegia & 2 \\
Problems related to eyesight & 2 \\
Laminectomy & 1 \\
Spina bifida & 1 \\
Muscular dystrophy & 1 \\
Poliomyelitis & 1 \\
Polymyositis & 1 \\
De Quervain's condition & 1 \\
Psoriatic arthritis & 1 \\
Hard of hearing & 1
\end{tabular}

Table I lists the diagnoses as given by the visitors; the range is wide but much as would be expected from national surveys of chronic disability. ${ }^{5}$ Twenty six $(40 \%)$ patients had a rheumatological condition and 24 (37\%) a neurological condition, which in most cases was chronic. Over half the patients were registered disabled.

\section{REFERRAL PATTERNS}

Of the 65 visitors, $44(68 \%)$ came from the city in which the centre is sited, a further $14(21 \%)$ lived within a radius of 15 miles, and the remaining seven 


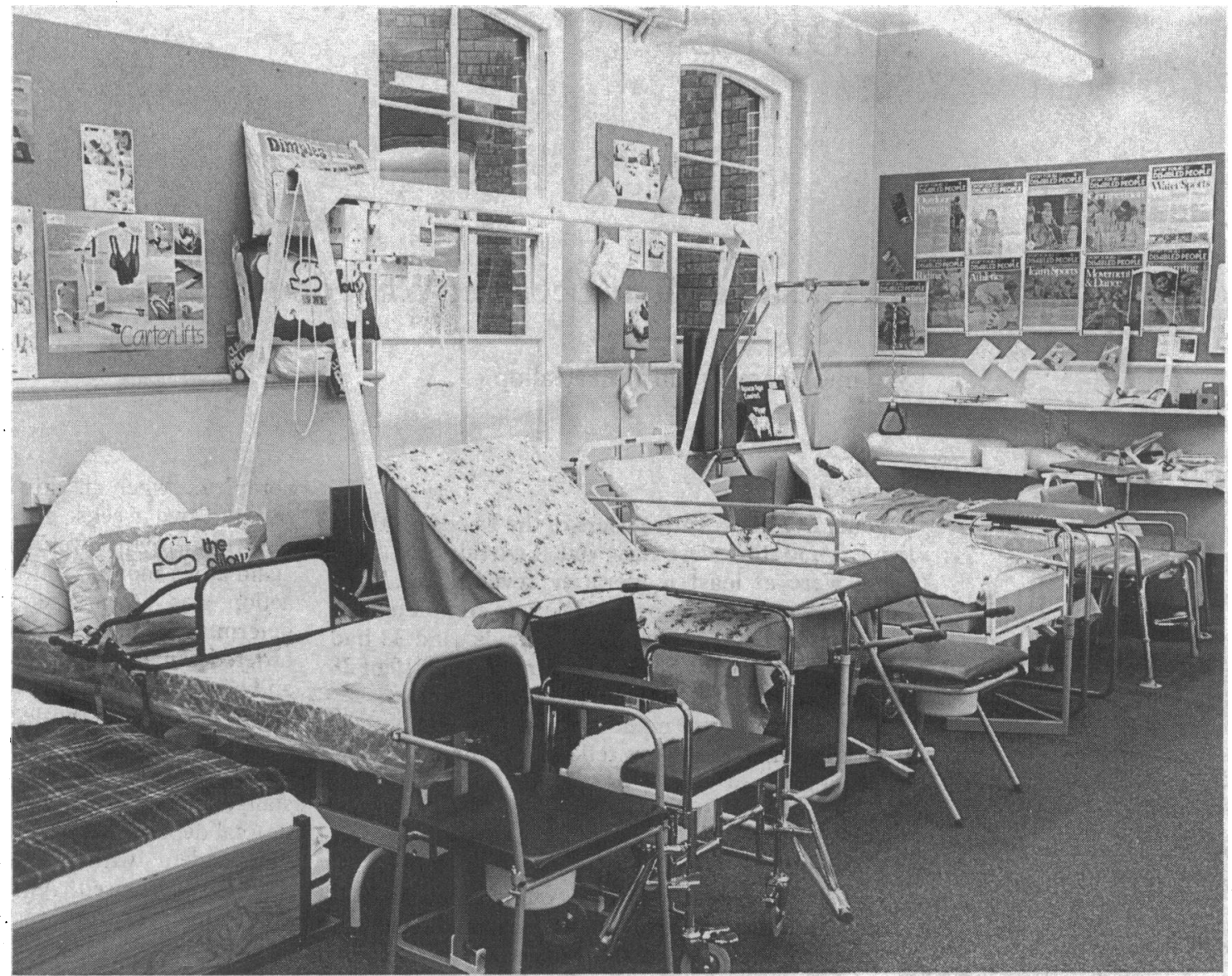

FIG 1-A selection of the equipment available at the William Merritt Disabled Living Centre, Leeds

came from a greater distance. Most lived in owner occupied houses; 14 lived alone, 12 of these being over age 60 , and nine of these considering themselves to be in unsuitable accommodation. Most came with a companion, usually a relative $(50)$ or professional worker (12).

Visitors knew about the centre from various sources, principally occupational therapists. Three general practitioners had told patients of the centre, as had one hospital doctor. Several visitors received information from newspapers, TV, and posters (distributed to all general practitioners when the centre opened). The referrals to the centre came predominantly from occupational therapists. Over a quarter of visitors (28\%) had referred themselves. Four had visited the centre before, 16 came for "a general look round," but $45(69 \%)$ had a specific problem to be solved.

\section{PROFILE OF DISABILITY}

Visitors had a great number of physical disabilities and appreciably impaired mobility: $23(35 \%)$ stated that they were unable to move around every room of their house, and $41(63 \%)$ were unable to manage the stairs. The level of disability outside the home was considerable (table II), and a considerable number used mobility aids: $21(42 \%)$ used a wheelchair inside the house and $36(55 \%)$ outside the house, and 25 (38\%) used sticks or crutches. Decreased mobility was also reflected in the low scores for the use of stairs and participation in leisure activities.

Table III shows that most were able to feed themselves, but many had difficulty with cooking and bathing in particular. Using the same crude grading of physical ability, the visitors divided almost equally into three groups of slight, moderate, and severe disability (table IV). This is reflected in the use they had made of many statutory services during the year immediately before their visit. Table $\mathrm{V}$ shows a considerable dependence on district nursing and home help (daily) services, with many also having used intermittent services of therapists, chiropodists, and social workers. Most (63\%) visitors needed more than one service, indicating the severity or multifactorial nature of their disability, or both.

TABLE II-Distance visitors managed to walk with reasonable ease

\begin{tabular}{lc}
\hline Distance & No $(\%)$ \\
\hline 1 mile $(1.6 \mathrm{~km})$ or more & $4(6)$ \\
More than 100 yards $(91 \mathrm{~m})$ but less than & $7(11)$ \\
1 mile $(1.6 \mathrm{~km})$ & $9(14)$ \\
Only $50-100$ yards $(46-91 \mathrm{~m})$ & $24(37)$ \\
Less than 50 yards $(46 \mathrm{~m})$ & $19(29)$ \\
Can't manage at all & $2(3)$ \\
Did not answer &
\end{tabular}

TABLE III-Average score for ability

\begin{tabular}{lc}
\hline Activity assessed & Average score $^{\star}$ \\
\hline Feeding & 9 \\
Toileting & 9 \\
Dressing & 8 \\
Cooking & 6 \\
Bathing & 6 \\
Leisure Activities & 6 \\
Stairs & 5 \\
General mobility & 5 \\
\hline
\end{tabular}

${ }^{\star} 10=$ independent $5=$ needs some help; $0=$ total dependency.

TABLE IV-Assessment scores for physical disability in eight activities (giving total scores of a possible 80)

\begin{tabular}{lc}
\hline Scores* & No (\%) of visitors \\
\hline $61-80$ & $21(32)$ \\
$41-60$ & $22(34)$ \\
$21-40$ & $12(18)$ \\
$0-20$ & $9(14)$ \\
Did not answer question & $1(2)$
\end{tabular}

$\star$ For each of eight activities $10=$ independent; $5=$ needs some help; $0=$ independent. 
TABLE V-Analysis of services used by visitors during the year before visiting the disabled living centre

\begin{tabular}{lc}
\hline Service used & Frequency of use \\
\hline Occupational therapist & 32 \\
Social worker & 26 \\
Physiotherapist & 25 \\
Chiropodist & 22 \\
District nurse & 17 \\
Home help & 15 \\
Health visitor & 10 \\
Meals on wheels & 6 \\
Speech therapist & 4 \\
Other: & 18 \\
General practitioner & 11 \\
Hospital doctor & 4 \\
Aids and adaptation officer & 2 \\
Day hospital & 1 \\
\hline
\end{tabular}

\section{PROVISION OF AIDS AND ADAPTATIONS}

Before their visit to the centre $50(77 \%)$ visitors were already using some aids or equipment, principally small aids and mobility aids; 36 (55\%) already had some form of adaptation installed in the home, mainly rails and ramps.

After assessment at the centre many aids and adaptations were recommended to visitors. Forty eight visitors were considered to need aids (usually several), and 29 of these referred themselves to the relevant loca authority or community health department or purchased the item themselves. Ten, however, did nothing at all, and by the end of the survey a further five had not received their equipment either. Less than half had received all suggested articles of equipment, even though most of these were relatively simple and inexpensive (fig 2). Indeed, a quarter of the aids were obtained privately by the disabled visitors, half were funded from social services, and a few were funded by the health services. The average time to receipt of aids was six weeks. Most visitors appeared to be satisfied with what was provided (average score of $3 \cdot 2$ on a scale of 1-4).

Adaptations presented a greater problem. A total of 28 adaptations were suggested, but 18 had not been received by the end of the survey. Nineteen recommended adaptations were stairlifts. Of these, 19 stairlifts had been ordered and seven had been installed at the time we completed follow up. None of these stairlifts had been paid for by the disabled person as far as we knew, in two cases the source of funding was unknown, in five cases the local authority had funded the adaptation. In all of these instances there was considerable delay.

\section{Discussion}

There are now 10200 technical aids and pieces of equipment listed on the disabled living foundation's databank, and over the past decade these have become more complex and refined so that the need for resource centres to help maximise their use has become progressively more important since the first centre was founded in London in 1971. Yet we still know little about how the centres work as little has been published about them. Moreover, the staff of the centres rarely

\begin{tabular}{|c|c|c|c|c|}
\hline Total No of visitors & & $\begin{array}{l}\text { Recommendation } \\
\text { of aids }\end{array}$ & $\begin{array}{l}\text { Ordering } \\
\text { of aids }\end{array}$ & $\begin{array}{l}\text { Receipt of aids } \\
\text { by end of survey }\end{array}$ \\
\hline \multirow{3}{*}{65} & \multirow{3}{*}{48} & $\begin{array}{l}18 \text { Recommended } \\
\text { more than one }\end{array}$ & $\begin{array}{l}29 \text { Ordered all } \\
\text { recommendations }\end{array}$ & $\begin{array}{l}22 \text { Received all those } \\
\text { recommended }\end{array}$ \\
\hline & & $\Rightarrow 48$ & 9 Ordered some & 11 Received some \\
\hline & & $\begin{array}{l}30 \text { Recommended } \\
\text { only one }\end{array}$ & 10 Ordered nothing & $\begin{array}{l}15 \text { Received none } \\
\text { (including } 5 \text { visitors } \\
\text { who died after } \\
\text { placing an order) }\end{array}$ \\
\hline
\end{tabular}

FIG 2-Recommendations made for aids for disabled visitors to Leeds centre and outcome know what happens about their recommendations, how useful they have been to their clients, or even whether those clients were able to follow up their recommendations

Few visitors to the Leeds disabled living centre came solely out of curiosity. Most were moderately or severely disabled. Many had problems in several functional areas, which justifies the decision to allot sufficient time to each visitor to deal with more than the presenting need. Many had already been provided with some aids or adaptations and yet they sought more: the medical profession rarely deals with this requirement for review of equipment needs, yet our findings suggest that this would be helpful. Beattie showed that many patients with parkinsonism require regular review of their need for aids. ${ }^{6}$

The Leeds centre, like others, is accessible to those who use walking aids and wheelchairs. It is busy yet it is rarely used by people who live further than 15 miles away from it. We have regularly publicised the centre since its inception-on television, radio, and in the local press. Study days are organised regularly. Medical students, students of virtually every paramedical profession, and workers in the local social services department are taught. Courses can be organised to suit the needs of any group. Nevertheless, these professionals (occupational therapists excepted) do not seem to recognise the value of this resource to their patients. Is it because it is in a non-traditional form where visitors (or patients) are helped to make their own decisions? Or is it because doctors still perceive disease but not disability ${ }^{4}$ Given the little time devoted to disability medicine in the medical school curriculum this may be understandable, but all medical students should visit these centres. It is also evident that many disabled people still do not know about the technical aids they need to cope with life. The centres may have to use more aggressive publicity to reach these people, or more centres may have to be established.

Our findings confirm that disabled people usually wait an unacceptably long time for both equipment and adaptations. Such delay has been documented many times, ${ }^{7}$ though in Leeds it was relatively satisfactory with respect to equipment, but delay was experienced when large or expensive equipment was needed, principally stairlifts. Some of this might have been attributable to the need for referral to community occupational therapists and assessment of the home, as well as difficulties with funding.

Nevertheless, delay may be very important when disease is rapidly progressive, as in motor neurone disease. It is common to find aids and adaptations arriving after a person has died. ${ }^{8}$ In Leeds this is often avoided by alerting the disability officer in the social services department, but the diagnosis needs to be known. Open access is a valuable asset of all centres, but it would have been helpful to staff to know the diagnosis - for example, in the five cases where the patient had died during the short period of our follow up.

Disabled living centres do good work and provide information and advice on technical aids for disabled people to both professionals and disabled visitors. They deserve to be better known, and it is the responsibility of professionals, including doctors, to ensure that those in need of the service find their way to a centre.

We thank Mrs S Tunstall, manager of the Disabled Living Centre, Mrs Janet Stowe, senior research occupational therapist, the staff of the disabled living centres and their visitors, Mrs J Packter who gave secretarial help, and Nicholas Gallop for skilful analysis of the data. We also thank 
the management council of the William Merritt Centre for funding the study.

1 Anonymous. Physical disability 1986 and beyond. I R Coll Physicians Lond 1986;20:160-94.

2 Jeff O, Chamberlain MA. Survey of aids centres 1978-79. British foumal of Occupational Therapy 1979;42:308-12.

3 Aina $\mathrm{OO}$. An evaluative study of an aid and equipment centre: reference to clients' satisfaction with level of independence [Dissertation]. Southampton: University of Southampton, 1986
4 Stowe J. Disabled living centres. I R Coll Gen Pract 1988;38:34-5.

Harris A. Handicapped and impaired in Great Britain. Part I. London: HMSO, 1971

6 Beattie A. Aids to daily living for the patient with Parkinson's disease. British Journal of Occupational Therapy 1981;44:53-6.

Keeble U. Occasional papers on social administration. No 62. London: Bedford Square Press and the National Council of Social Services, 1979.

8 Newrick PG, Langton-Hewer R. Motor neurone disease: can we do better? A studv of 42 patients. $\operatorname{Br}$ Med $\mathcal{f}$ 1984;289:539-42.

Accepted 3 October 1988)

\title{
Lesson of the Week
}

\section{Pituitary apoplexy}

\author{
I G Lewin, J Mohan, P F Norman, R A Gibson, J R C Francis
}

Pituitary apoplexy may occur without evidence of prior endocrine dysfunction and may simulate aneurysmal subarachnoid haemorrhage

\section{North Devon District Hospital, Barnstaple Devon EX31 4JB I G Lewin, FRCPED, consultant physician R A Gibson, FRCSED, consultant ophthalmologist J R C Francis, MB, senior house officer}

Derriford Hospital, Plymouth, Devon PL6 8DH J Mohan, FRCS, consultant neurosurgeon

P F Norman, FRCR, consultant neuroradiologist

Correspondence to: Dr Lewin.
Pituitary apoplexy, a complication of pituitary adenomas, is characterised by sudden headache, visual impairment, and ophthalmoplegia and is usually associated with haemorrhagic infarction of the tumour. This condition may be mistaken for aneurysmal subarachnoid haemorrhage, and the true diagnosis may be delayed or even remain unsuspected because the underlying pituitary adenoma is frequently not clinically apparent. ${ }^{\prime}$ We describe a case of pituitary apoplexy in which urgent computed tomography (CT) and cerebral angiography were essential to establish the diagnosis.

\section{Case history}

A 61 year old right handed man with no medical history of note suffered sudden onset of giddiness, vomiting, and headache, which worsened over the next two days. On admission soon afterwards he was stuporous and dysphasic with a complete third nerve palsy on the left. Visual fields could not be tested accurately because of poor comprehension, but other cranial nerves and fundi were normal. He had photophobia and mild neck stiffness but no pulsatile exophthalmos and no cranial or vascular bruits. There was spontaneous movement in all limbs, tone was normal, reflexes were brisk and symmetrical, and plantar responses were flexor. He was in sinus rhythm at 90 beats $/ \mathrm{min}$, heart sounds were normal, and blood pressure was $160 / 90 \mathrm{~mm} \mathrm{Hg}$. He had a fever of $38 \cdot 4^{\circ} \mathrm{C}$; respiratory system, abdomen, thyroid, and body hair distribution were all normal. Chest $x$ ray appearances and an electrocardiogram were normal.

He was initially suspected of having an aneurysmal subarachnoid haemorrhage with a left temporoparietal haematoma. Skull radiographs, however, showed a slightly expanded pituitary fossa with possible early erosion of the anterior clinoid process and the petrous apex on the left. CT of the head showed high density material in the pituitary fossa and suprasellar region extending into the left sylvian fissure. With contrast enhancement a small oval structure was visualised in the left suprasellar region. This appearance was consistent with either subarachnoid haemorrhage from a parasellar aneurysm or pituitary apoplexy. Next day he continued to deteriorate with deepening stupor, loss of all eye movements on the left, progressive right hemiparesis, and a fall in blood pressure to $90 / 60$ $\mathrm{mm} \mathrm{Hg}$. He was given intravenous dexamethasone and volume repletion and subjected to urgent bilateral carotid angiography via a right femoral approach. Displacement of vessels on the left indicated a lesion above the pituitary fossa which extended superiorly and laterally towards the temporal fossa and which was consistent with pituitary apoplexy. Immediate left frontoparietal craniotomy was performed. A large haemorrhagic tumour was seen arising from the pituitary fossa, encircling the optic chiasm and optic nerves, and extending leftwards, lateral to the internal carotid artery and the cavernous sinus, back to the membrane of Liliequist. It was evacuated by Cavitron ultrasonic suction apparatus with preservation of the optic chiasm and nerves. Histologically the pituitary tissue showed extensive haemorrhage and small numbers of uniform adenoma cells with negative immunocytochemical staining for prolactin and growth hormone.

Postoperatively the patient was given replacement therapy with hydrocortisone, thyroxine, and testosterone. Two weeks and also two years later triple bolus testing showed no appreciable function of the anterior pituitary, so replacement therapy was continued in the long term. Diabetes insipidus was not a problem, with a normal rise in urinary osmolality on water deprivation. His left third and fourth nerve lesions persisted after more than two years, but there was recovery of the sixth nerve paralysis. Visual field testing showed an incomplete right homonymous hemianopia with macular sparing, and the remaining left temporal visual field was reduced. Corrected visual acuities were right $6 / 7 \cdot 5$, left $6 / 12$. Both optic discs, particularly the left, were paler than normal. He was troubled by mild nominal dysphasia and memory disturbance but the right hemiparesis had resolved. $\mathrm{He}$ gave no retrospective history of endocrine dysfunction antedating his episode of pituitary apoplexy. Serial CT scans of the head showed evidence of old infarction in the left temporal lobe but no recurrence of the pituitary tumour.

\section{Discussion}

Pituitary apoplexy is becoming increasingly recognised as a complication of pituitary adenomas, ${ }^{2}$ occurring in over $10 \%$ of cases. ${ }^{1}$ Manifestations typically include headache, meningeal irritation, and visual loss or ophthalmoplegia, or both, with additional features depending on the extent of spread of hypophysial contents and haemorrhage. In our patient lateral spread caused ophthalmoplegia, whereas spread to the temporal lobe resulted in prolonged dysphasia and memory disturbance. Clinically pituitary apoplexy may be difficult to differentiate from aneurysmal subarachnoid haemorrhage and it may be unsuspected because signs and symptoms of prior endocrine dysfunction are absent in most cases. ${ }^{1}$ Occasionally pituitary apoplexy develops slowly over several weeks, but usually it follows a similar time course to that of aneurysmal subarachnoid haemorrhage and evolves fully within two days.' 